\title{
Environmental Consequences of Potential Strategies for China to Prepare for Natural Gas Import Disruptions
}

\author{
Yue Qin,* Mi Zhou, Da Pan, Zbigniew Klimont, Daniel B. Gingerich, Denise L. Mauzerall, Lei Zhao, \\ Gang He, and Jeffrey M. Bielicki
}

Cite This: https://doi.org/10.1021/acs.est.1c03685

Read Online

ACCESS | Lلlll Metrics \& More | 国 Article Recommendations | St Supporting Information

ABSTRACT: Worldwide efforts to switch away from coal have increased the reliance on natural gas imports for countries with inadequate domestic production. In preparing for potential gas import disruptions, there have been limited attempts to quantify the environmental and human health impacts of different options and incorporate them into decision-making. Here, we analyze the air pollution, human health, carbon emissions, and water consumption impacts under a set of planning strategies to prepare for potentially fully disrupted natural gas imports in China. We find that, with China's current natural gas storage capacity, compensating for natural gas import disruptions using domestic fossil fuels (with the current average combustion technology) could lead up to 23,300 (95\% CI: 22,100-24,500) excess premature deaths from air pollution, along with increased carbon emissions and aggravated water stress. Improving energy efficiency, more progressive electrification and

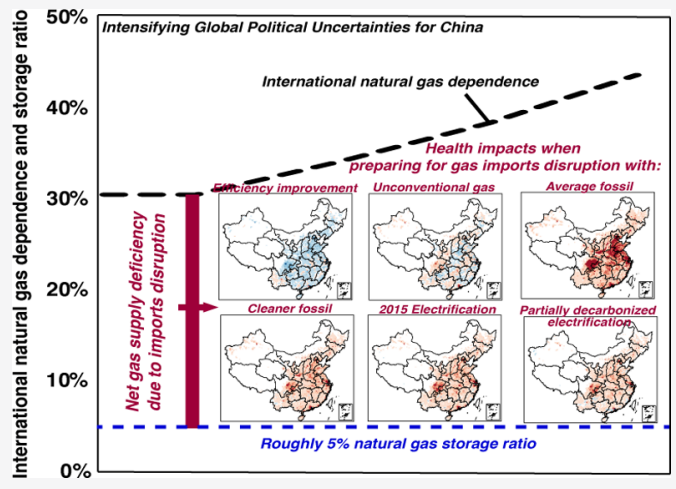
decarbonization, cleaner fossil combustion, and expanding natural gas storage capacity can significantly reduce the number of excess premature deaths and may offer opportunities to reduce negative carbon and water impacts simultaneously. Our results highlight the importance for China to increase the domestic storage capacity in the short term, and more importantly, to promote a clean energy transition to avoid potentially substantial environmental consequences under intensifying geopolitical uncertainties in China. Therefore, mitigating potential negative environmental impacts related to insecure natural gas supply provides additional incentives for China to facilitate a clean and efficient energy system transition.

KEYWORDS: energy security, energy self-reliance, electrification and decarbonization, energy efficiency, natural gas storage, air quality and human health, water demand, greenhouse gas emissions

\section{INTRODUCTION}

Natural gas is widely considered to be the cleanest burning fossil fuel which, along with its flexible use for cooking and heating, electricity generation, and transportation, has facilitated its utilization as a bridge toward an ultimately carbon- and air pollution-free energy future. ${ }^{1-3}$ Although not as desirable as nonfossil energy, assuming appropriate source choices $^{4,5}$ and deployment strategies, ${ }^{6}$ and effective methane leakage control, ${ }^{7-9}$ natural gas substitution for other fossil fuels can bring tangible air quality, climate, and water co-benefits. ${ }^{6,10}$

Globally, natural gas has been the fastest growing fossil fuel over the past decade, supplying one-third of worldwide energy demand growth. ${ }^{11}$ However, only a few countries' rapidly growing natural gas consumption is supported by comparable increases in domestic production as a result of technological breakthroughs and policy supports (i.e., the shale gas boom in the U.S.). ${ }^{12,13}$ For major developing economies such as China, increases in domestic natural gas production are far from adequate to meet their growing demand, ${ }^{14,15}$ resulting in serious concerns about national energy security (i.e., securing uninterrupted energy supply at affordable prices). ${ }^{16}$ In addition to high external dependence, China's natural gas imports are also exposed to a series of other threats, such as energy exporter's resource risks (e.g., decreasing resources left for exports due to increasing domestic demand in Yemen, Australia, and Uzbekistan) $)^{17}$ and political risks (e.g., political instability in Myanmar or Yemen conflicts in the Middle East); ${ }^{17,18}$ transportation risks endemic to the geography of China's shipping routes (e.g., long transport distance, weatherinduced maritime accidents, and Straits of Malacca as the geographical "choke points" exposed to pirate and terrorist attacks); ${ }^{17-20}$ as well as natural hazards, ${ }^{19}$ price volatility, ${ }^{17,18,21}$ purchasing power risks, ${ }^{17}$ and competition for geographically concentrated natural gas resources. ${ }^{20}$

Received: June 10, 2021

Revised: December 8, 2021

Accepted: December 9, 2021 


\section{Table 1. Energy Sector Scenarios to Prepare for International Natural Gas Supply Disruptions ${ }^{a}$}

preparation scenarios

energy efficiency improvement

unconventional gas compensation

average fossil compensation

cleaner fossil compensation

2015 electrification

partially decarbonized electrification

\section{description}

improve end-use energy efficiency to make up for international natural gas cuts

develop domestic unconventional natural gas to compensate for international natural gas cuts

use domestic fossil fuels (with current average combustion technology) to compensate for international natural gas disruptions. Coal is used to compensate for natural gas used in all major sectors

(i.e., residential, industrial, and power sectors); oil is used in the transportation sector ${ }^{b}$

the same as above, but use domestic fossil fuels with cleaner combustion technology

(lower EFs and higher energy efficiency) to compensate for international natural gas disruptions ${ }^{b}$

generate extra electricity to compensate for international natural gas disruptions with the 2015 power mix ${ }^{c}$

generate extra electricity to compensate for international natural gas disruptions with the 2030 power mix under stated policies $^{d}$

${ }^{a}$ Note the ultimate goal of each scenario is to keep the final energy service demand (e.g., residential heating demand) the same as that when without import disruptions. ${ }^{b}$ Details of energy efficiency and EFs used are provided in Table S1. ${ }^{c}$ Electricity is generated with the 2015 energy mix: approximately $74 \%$ thermal, $19 \%$ hydro, $3 \%$ nuclear, $3 \%$ wind, and $1 \%$ solar, following China's Electricity Statistic Yearbook. ${ }^{35}$ As we use electricity to compensate for the reduced natural gas supply, we will not use extra natural gas to generate additional electricity. Also, oil makes up less than $0.1 \%$ of the thermal electricity. Thus, here, we assume that additional thermal electricity is all provided by coal. ${ }^{d}$ Electricity is generated with the predicted 2030 average energy mix according to the World Energy Outlook Stated Policy Scenario: approximately 57\% thermal, 14\% hydro, 7\% nuclear, 3\% bioenergy, $10 \%$ wind, and $9 \%$ solar. ${ }^{36}$ Similar to the 2015 electrification scenario, as we use electricity to compensate for the reduced natural gas supply, we will not use extra natural gas to generate additional electricity. Thus, here, we assume that additional thermal electricity is all provided by coal.

Intensifying international relations are further aggravating China's concerns about international natural gas supply security and hence the security of its national economy. ${ }^{22,23}$ For example, the U.S.-China trade war suggests that the relationship between these two countries is worsening, and "tougher" policies toward China that view it as an emerging opponent tend to garner bipartisan support in the U.S. ${ }^{22}$ International suppliers of natural gas to China, such as the U.S. and its allies, may threaten China's natural gas supply either by directly banning exports to China or threatening China's oil and natural gas transportation lines. ${ }^{22}$

Unanticipated gas disruptions may lead to cascading problems in China's national economy, societal peace, and political stability. ${ }^{18,20,22}$ As a result, China's top leadership has called for national oil and gas companies to significantly increase domestic production to counteract the increasing external dependence that may impede China's sustainable socioeconomic development. ${ }^{18,23}$ Therefore, it is of critical importance for China to explore potential self-reliant planning strategies, as instructed by President Xi's directive, ${ }^{23}$ so as to prepare for potential import disruptions. That is, China should prepare to satisfy the predisturbance end-use energy service demand via upgrading its domestic energy system.

To prepare for potential natural gas import disruptions, gasimporting countries could transform their domestic energy sector either by using available gas storage, further improving end-use energy efficiency, or switching to alternative fuels. Different planning strategies for gas import disruptions will result in varying degrees of environmental impacts when implemented, with some pathways that may lead to severe environmental consequences; hence, cautious cross-strategy analysis is needed to better inform decision-making. Nevertheless, previous studies have primarily focused on identifying the drivers and severity of natural gas insecurity, ${ }^{14,24-26}$ and/or evaluating the geopolitical and financial risks associated with natural gas imports, ${ }^{27,28}$ whereas the associated environmental outcomes have rarely been evaluated. Limited relevant studies mostly highlight energy security as a co-benefit of climate policies, ${ }^{29-31}$ while only a few efforts provide insights on the reverse impacts of energy independence on greenhouse gas emissions (GHG). ${ }^{32}$ To date, few studies have systematically analyzed the underlying multiaspect environmental conse- quences that could result from natural gas-importing countries' planning strategies in anticipation of disrupted international trade.

Here, we characterize the environmental consequences of potential planning scenarios that focus on upgrading the domestic energy system to prepare for a complete disruption of natural gas imports. The impacts are estimated assuming that planning scenarios are rooted in the 2015 energy system structure and level of pollution control due to data availability (Supporting Information). A complete shutdown of natural gas imports is at the limit of disruption and thus presents the potential maximum environmental impacts of each scenario, yet preparing for the need for self-reliance adds flexibility and geopolitical leverage. Our study does not seek to predict the possibility or severity of international natural gas market interruptions but rather answer the following questions: for natural gas-importing countries such as China, given their current storage capacity and energy system, what would the environmental consequences be when they pursue different strategies to prepare for gas import disruptions, and how could these environmental consequences be minimized?

\section{MATERIALS AND METHODS}

This work evaluates the potential multiaspect environmental impacts of a set of domestically planning scenarios for China to prepare for disruptions due to insecure natural gas supply. We use an integrated assessment framework coupled with life cycle analysis. We simulate national and spatially resolved air quality (and associated human health), GHGs, and water consumption impacts for each scenario, which is designed to provide the energy that would be lost in the event of a full disruption of international natural gas supply under China's current energy structure and natural gas storage capacity.

Planning Scenarios' Design. In 2015, China's natural gas dependence on international imports was around $30 \%,{ }^{33}$ while its underground gas storage ratio was roughly $5 \%$, far below the global average of about $12 \% .^{34}$ We define the differences between country-level annual total undisturbed natural gas imports and national total natural gas storage as the "domestic gas supply deficiency" due to international gas disruptions, which is at the magnitude of $25 \%$ of China's total natural gas consumption in 2015 under current storage capacity. 
To prepare for this domestic (within the country) natural gas supply deficiency, we design six major planning scenarios based on the 2015 storage capacity and energy system structure, as shown in Table 1: (1) improving energy efficiency across end-uses, (2) facilitating domestic unconventional natural gas [e.g., shale gas and synthetic natural gas (SNG)] development as alternative natural gas supplies, (3) compensating for natural gas import disruptions with increasing domestic fossil fuels with the current fuel mix and combustion technology, (4) compensating for gas import disruptions with increasing domestic fossil fuels with cleaner combustion technology, (5) compensating for gas import disruptions with increasing electricity generated with the 2015 power sector mix (74\% fossil fuel and $26 \%$ nonfossil energy), ${ }^{35}$ and (6) compensating for natural gas import disruptions with electricity generated with a partially decarbonized power sector fuel mix ( $57 \%$ fossil fuel and $43 \%$ nonfossil energy). ${ }^{36}$ These six scenarios provide a relatively representative coverage of China's potential planning strategies to meet its predisruption end-use energy service demand.

Emissions and Water Consumption. Comparing emissions and water consumption under each of our designed scenarios with the baseline (undisturbed international gas imports), we quantify their respective changes in air pollutant emissions, GHGs, and water consumption.

Using eqs 1-4, we first estimate China's spatial and sectoral heterogeneity in the required overall energy efficiency improvement and alternative energy demand for each scenario based on China's 2015 statistical energy data breakdown. ${ }^{33}$ Major end-use energy efficiency and fuel economy parameters used in this calculation are shown in Table S1. Lacking information of sector- and province-specific external gas dependence, we assume gas import interruption will affect each sector and each province in proportion to their baseline natural gas consumption. This is because China has relatively well-connected natural gas pipeline infrastructure for interprovince gas flow across the country, and, thus, postdisruption natural gas re-allocation is likely to resemble the baseline pattern. On top of that, we further include a sensitivity analysis, assuming that provinces with higher political and economic priorities (i.e., Beijing and Shanghai) have higher priorities in postdisruption natural gas re-allocation and hence are less affected by import disruptions (Supporting Information).

We then calculate the changes in life cycle emissions and water consumption by integrating both upstream and end-use processes. Upstream air pollutant emissions, GHGs, and water consumption are calculated based on upstream emission intensities for air pollutants and greenhouse gases and water consumption intensities reported in earlier studies, ${ }^{6,37,38}$ together with our estimated alternative energy demand for each scenario. We then estimate end-use environmental changes using eqs 5 and 6 under each scenario primarily based on the ECLIPSE_V5a_CLE (evaluating the climate and air quality impacts of short-lived pollutants) emission scenario $^{39,40}$ developed with the GAINS model. For changes in end-use water consumption, we mainly rely on water consumption coefficients for industrial boilers reported in earlier studies, together with China's unit-level water consumption for natural gas and coal generation units. ${ }^{41}$ More methodological details are summarized in the Supporting Information.

Degree of efficiency improvement needed under the efficiency improvement scenario

$$
\begin{aligned}
\Delta \mathrm{EFI}_{\mathrm{r}, \mathrm{s}}= & \left(\mathrm{OE}_{\mathrm{r}, \mathrm{s}}+\operatorname{gas}_{\mathrm{r}, \mathrm{s}}\right) /\left(\mathrm{OE}_{\mathrm{r}, \mathrm{s}}+(1-(\alpha-\kappa)) * \operatorname{gas}_{\mathrm{r}, \mathrm{s}}\right) \\
& -1
\end{aligned}
$$

Alternative fuels needed to compensate for gas import disruptions under fossil compensation scenarios

$$
\Delta \mathrm{AF}_{\mathrm{r}, \mathrm{s}, \mathrm{q}}=(\alpha-\kappa) * \mathrm{gas}_{\mathrm{r}, \mathrm{s}} * Q_{\mathrm{r}, \mathrm{s}, \mathrm{q}} * \eta_{t, \mathrm{gas}} / \eta_{t, \mathrm{AF}}
$$

Extra electricity needed to compensate for gas import disruptions under electrification scenarios

$$
\Delta \mathrm{ELE}_{\mathrm{r}, \mathrm{s}, \mathrm{q}}=(\alpha-\kappa) * \operatorname{gas}_{\mathrm{r}, \mathrm{s}} * Q_{\mathrm{r}, \mathrm{s}, \mathrm{q}} * \eta_{t, \mathrm{gas}} / \eta_{t, \mathrm{ELE}}
$$

Additional fuels needed to generate extra electricity estimated in ref 3

$$
\Delta \mathrm{AF}_{\mathrm{r}, \mathrm{s}, \mathrm{q}, \mathrm{ELE}}=\Delta \mathrm{ELE}_{\mathrm{r}, \mathrm{s}, \mathrm{q}} / \eta_{e, \mathrm{AF}}
$$

Changes in emissions or water consumption under each scenario due to decreased gas use

$$
\Delta E_{\mathrm{gas}, \mathrm{m}, \mathrm{r}, \mathrm{s}, \mathrm{q}}=(\alpha-\kappa) * \mathrm{gas}_{\mathrm{r}, \mathrm{s}, \mathrm{q}} * \mathrm{EF}_{\mathrm{gas}, \mathrm{m}, \mathrm{r}, \mathrm{s}, \mathrm{q}}
$$

Changes in emissions or water consumption under each scenario due to increased alternative fuel use

$$
\Delta E_{\mathrm{AF}, \mathrm{m}, \mathrm{r}, \mathrm{s}, \mathrm{q}}=\Delta \mathrm{AF}_{\mathrm{r}, \mathrm{s}, \mathrm{q}} * \mathrm{EF}_{\mathrm{AF}, \mathrm{m}, \mathrm{r}, \mathrm{s}, \mathrm{q}}
$$

r: region; s: sector (e.g., the residential sector); $\alpha$ : China's natural gas foreign dependence, $30 \%$ in 2015; $\kappa$ : China's underground natural gas storage ratio, roughly 5\% in 2015; q: subsector (e.g., residential cooking); $\eta$ : technology efficiency; t: technology (e.g., natural gas combined cycle); ELE: electricity amount; $E$ : emissions or water consumption; EF: emission factors or water consumption coefficients; $\Delta \mathrm{EFI}_{\mathrm{r}, \mathrm{s}}$ required overall energy efficiency improvement in region $r$ and sector $s$ to provide the same amount of end-use energy (e.g., electricity generation) as that without import disruptions; $\mathrm{OE}_{\mathrm{r}, \mathrm{s}}$ : baseline energy consumption other than natural gas in region $\mathrm{r}$ and sector $\mathrm{s}$, units are in $\mathrm{kg}$ coal equivalent ( $\mathrm{kg}$ coal eq); $\operatorname{gas}_{\mathrm{r}, \mathrm{s}}$ : total domestic and international natural gas consumption without trade disruptions ( $\mathrm{kg}$ coal eq); $\Delta \mathrm{AF}_{\mathrm{r}, \mathrm{s}, \mathrm{q}}$ : quantity of alternative fossil fuels needed to compensate for natural gas import disruption in region $r$, sector $s$, and subsector $\mathrm{q}$ ( $\mathrm{kg}$ coal eq); $Q_{\mathrm{r}, \mathrm{s}, \mathrm{q}}$ : the ratio of natural gas consumption in subsector $\mathrm{q}$ within sector $\mathrm{s}$ in region $\mathrm{r}$ to total gas consumption in sector $\mathrm{s}$ in region $\mathrm{r} ; \Delta \mathrm{ELE}_{\mathrm{r}, \mathrm{s}, \mathrm{q}}$ : quantity of extra electricity needed to compensate for natural gas import disruption in region $\mathrm{r}$, sector $\mathrm{s}$, and subsector $\mathrm{q}$ under electrification scenarios, units are in kg coal eq; $\Delta \mathrm{AF}_{\mathrm{r}, \mathrm{s}, \mathrm{q}, \mathrm{ELE}}$ : quantity of additional alternative fuels used to generate the required extra electricity estimated as $\Delta \mathrm{ELE}_{\mathrm{r}, \mathrm{s}, \mathrm{q}}$ ( $\mathrm{kg}$ coal eq); $\eta_{\mathrm{e}, \mathrm{AF}}$ : energy efficiency of alternative fuels in generating electricity; $\Delta E_{\mathrm{gas}, \mathrm{m}, \mathrm{r}, \mathrm{s}, \mathrm{q}}$ : reduced air pollutant emissions or water consumption from reduced natural gas consumption in region $\mathrm{r}$, sector $\mathrm{s}$, and subsector $\mathrm{q}$ for pollutant species or water (m); $\Delta \mathrm{E}_{\mathrm{AF}, \mathrm{m}, \mathrm{r}, \mathrm{s}, \mathrm{q}}$ : increased air pollutant emissions or water consumption from increased alternative fuel consumption in region $\mathrm{r}$, sector $\mathrm{s}$, and subsector $\mathrm{q}$ for pollutant species or water $(\mathrm{m}) ; \mathrm{EF}_{\mathrm{gas}, \mathrm{m}, \mathrm{r}, \mathrm{s}}$ : EFs or water consumption coefficients for natural gas used in region $r$, sector $s$, and subsector $q$ for pollutant species or water $(\mathrm{m}) ; \mathrm{EF}_{\mathrm{AF}, \mathrm{m}, \mathrm{r}, \mathrm{s}, \mathrm{q}}$ : $\mathrm{EFs}$ or water consumption coefficients for alternative fossil fuels used in region $\mathrm{r}$, sector $\mathrm{s}$, and subsector $\mathrm{q}$ for pollutant species or water $(\mathrm{m})$. Average and the 25th percentile EFs are used under the average fossil (AF) compensation and cleaner fossil (CF) 

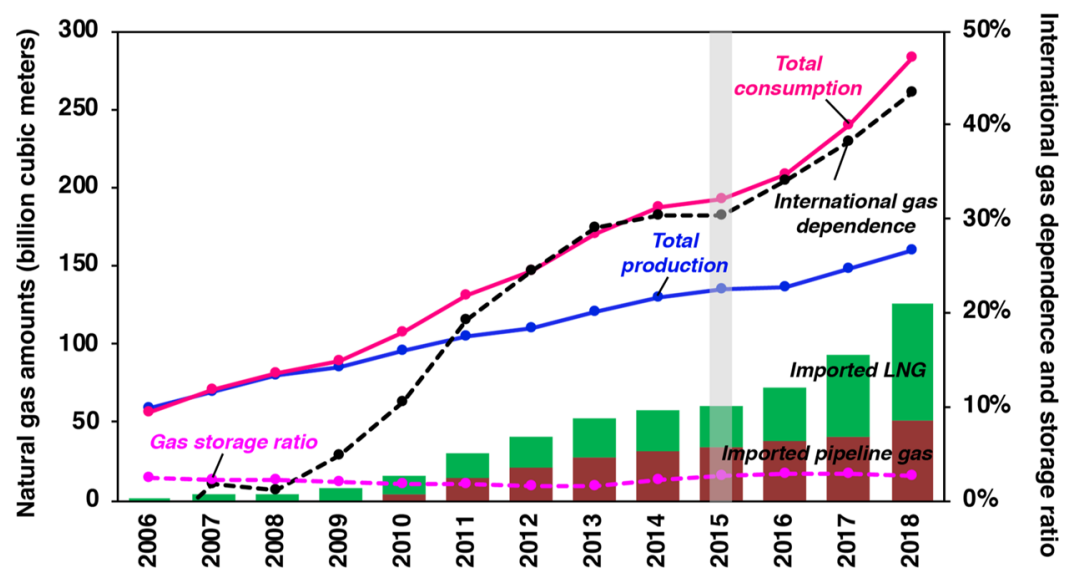

Figure 1. China's dependence on natural gas imports and natural gas storage ratio. Colored vertical bars show China's natural gas imports via pipeline gas (red) and liquefied natural gas (green) from 2006 to 2018. Solid blue, solid red, dashed black, and dashed magenta lines represent China's total natural gas production, consumption, foreign dependence (share of total consumption from imports), and underground natural gas storage ratio (the ratio of working gas to total gas consumption) over the same period, respectively. China has gone through rapidly increasing dependence on natural gas imports and is facing increasing insecurity in natural gas supply. We focus on the 2015 data in the main study, while we emphasize that natural gas foreign dependence has been continually increasing after 2015.

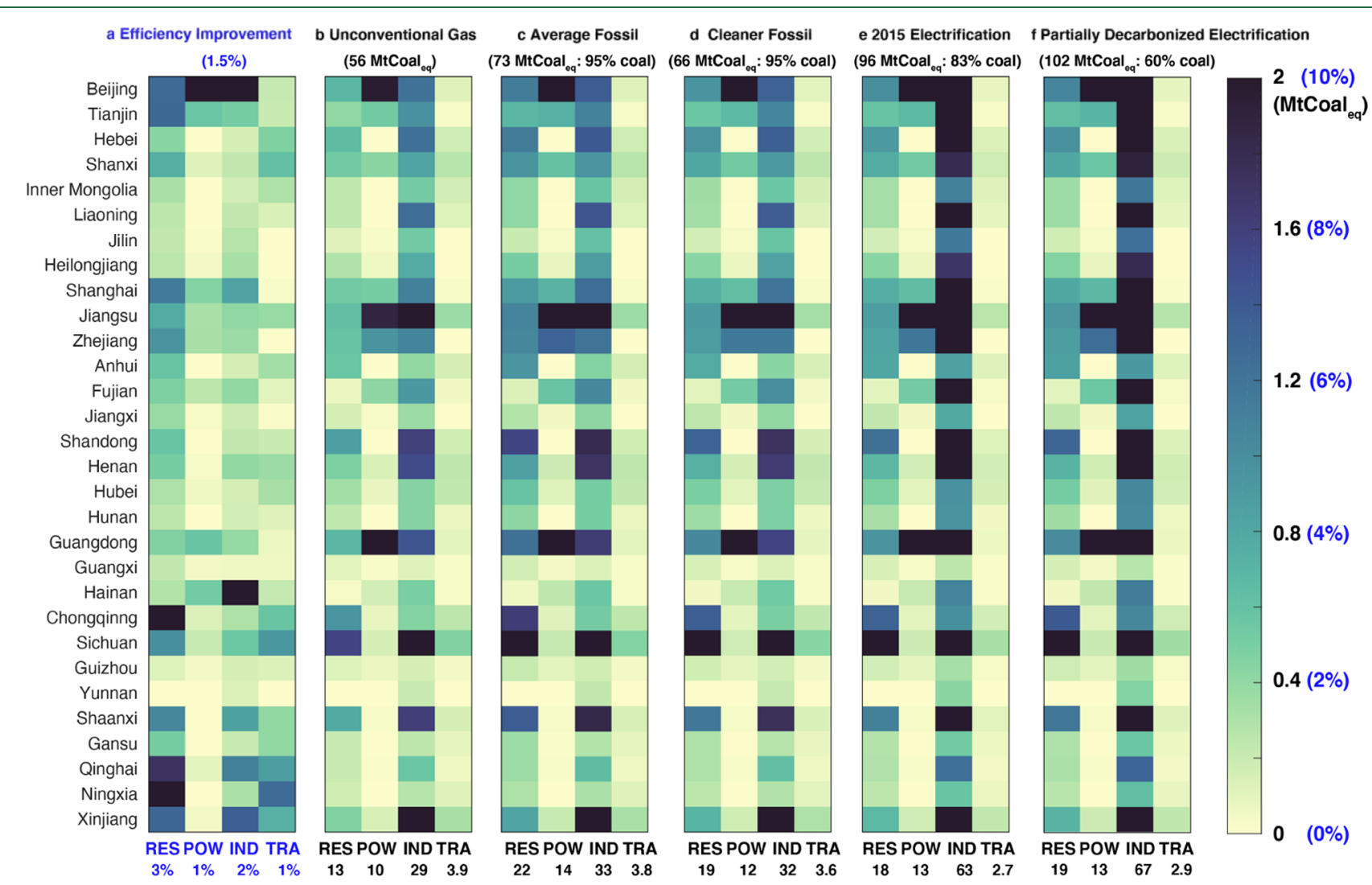

Figure 2. Required efficiency improvement or alternative energy in each scenario to prepare for potential natural gas import disruption. Heatmaps highlight China's mainland provinces (excluding Tibet due to data unavailability) and four major sectors (RES: residential, POW: power, IND: industry, and TRA: transportation) that require the most substantial (a) energy efficiency improvement (in blue font) or (b-e) alternative energy (in black fonts) in six scenarios. Note that the total number in the electrification scenario includes alternative energy input of both fossil fuels and nonfossil energy. Here, we attribute the additional electricity needed (and the associated fuel uses for providing the electricity) to its demand sector (e.g., industry), instead of attributing it to the power sector. Numbers above the heatmap for each scenario are (a) national average efficiency improvement required or $(b-e)$ national total alternative energy demand and the respective coal fraction $(b-e)$ for the four major sectors.

compensation scenarios, respectively. For water consumption, the average water consumption coefficients for all generation fleets, or for all advanced generation fleets ( $\geq 600 \mathrm{MW})$, are used for the AF compensation and $\mathrm{CF}$ compensation scenarios, respectively.
Air Quality and Human Health Impacts. Based on the changes in spatially explicit life cycle air pollutant emissions under each scenario, we simulate the resulting changes in gridlevel $\mathrm{PM}_{2.5}$ surface concentrations using the Weather Research and Forecasting model coupled with Chemistry model (WRF- 


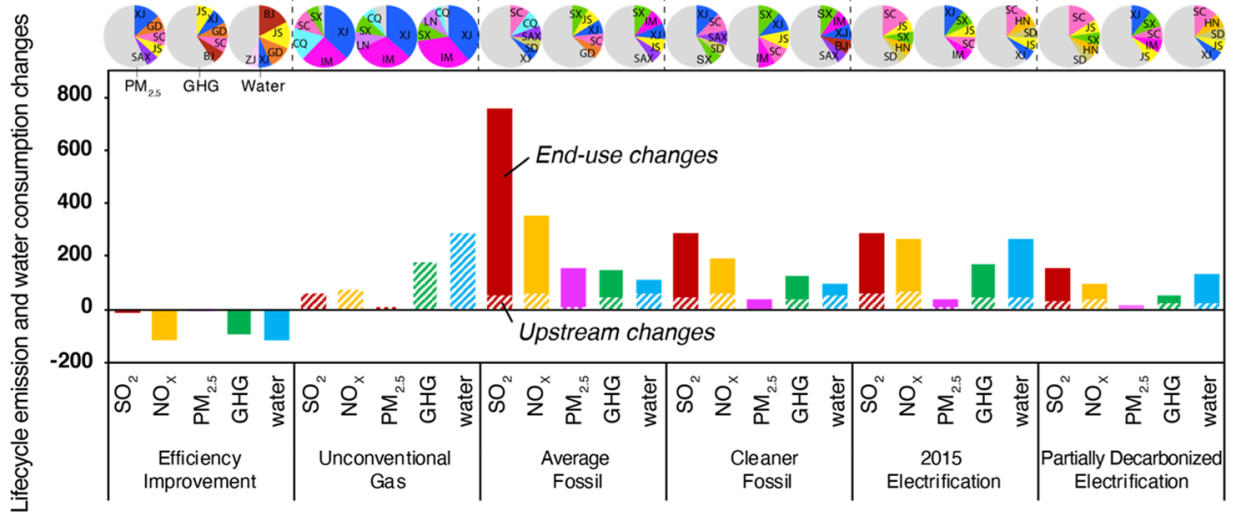

Figure 3. National multiaspect environmental impacts under each scenario. Vertical bars represent the changes in major air pollutant emissions $\left(\mathrm{SO}_{2}, \mathrm{NO}_{x}\right.$, and $\mathrm{PM}_{2.5}$ in kt), GHGs $\left(\mathrm{CH}_{4}\right.$ and $\mathrm{CO}_{2}$ together under $\mathrm{GWP}_{100}$ in $\left.\mathrm{Mt}\right)$, and water consumption $\left(\mathrm{Mm}^{3}\right)$ for both upstream (stripes) and end-use processes (solid). Note that for efficiency improvement and UN compensation scenarios, changes occur only in end-use and upstream processes, respectively. Other scenarios include changes in both upstream and end-use processes. We also show the regional share to $\mathrm{PM}_{2.5}\left(\mathrm{SO}_{2}\right.$ and $\mathrm{NO}_{x}$ are shown in Figure S2), GHG, and water consumption changes under each scenario with top pie charts. The spatial distribution of mainland China provinces is shown in Figure S1. XJ: Xinjiang, GD: Guangdong, SC: Sichuan, JS: Jiangsu, SAX: Shaanxi, BJ: Beijing, ZJ: Zhejiang, SX: Shanxi, IM: Inner Mongolia, CQ: Chongqing, LN: Liaoning, SD: Shandong, and HN: Henan. Gray areas in the pie charts indicate the total shares of all other non-top five provinces.

Chem v3.6.1)..$^{42,43}$ We use the same physical and chemical parameterizations as described by Zhou et al. $(2018)^{44}$ and adopt an improved scheme that factors into aerosol-radiation interaction to better represent the formation of secondary inorganic aerosols, which is essential for modeling air quality and calculating health impacts. ${ }^{45}$ Our model domain covers East Asia with a spatial resolution of $27 \times 27 \mathrm{~km}^{2}$. Annual average air quality simulations are represented with simulation results for January, April, July, and October for each scenario, with a 3 day spin-up for each monthly simulation (Figure S1).

On top of air quality simulations, we further evaluate the health impacts based on the updated Global Exposure Mortality Model. ${ }^{46}$ The updated relative risk (RR) equations developed by Burnett et al. (2018) ${ }^{46}$ are used in this study. We use Monte Carlo analysis to generate 100,000 shapes of RR to estimate the mean and $95 \%$ confidence intervals of avoided premature deaths under each scenario.

\section{RESULTS AND DISCUSSION}

Fast-Growing Natural Gas Import Dependence in China. Figure 1 provides a historical overview of China's natural gas supply and demand. China began importing liquefied natural gas (LNG) from Australia in 2006 and has been a net natural gas importer since the following year (Figure 1). ${ }^{47}$ From 2006 to 2018, natural gas consumption in China quintupled from 56 billion cubic meters $(\mathrm{bcm})$ to 283 $\mathrm{bcm}$, while domestic production only increased 2.7 times (from 59 to $160 \mathrm{bcm}$ ). ${ }^{33}$ Meanwhile, total natural gas imports in China rapidly expanded from $1 \mathrm{bcm}$ in 2006 to $126 \mathrm{bcm}$ in 2018 via pipeline gas $(\sim 52 \mathrm{bcm})$ and LNG $(\sim 74 \mathrm{bcm})$. As a result, China relied on natural gas imports for $\sim 45 \%$ of its demand in $2018,60 \%$ of which was from LNG. ${ }^{33}$

Despite the notably increasing foreign gas dependence, China's underground natural gas storage development has remained low. During the past decade, China's underground gas storage ratio-the ratio of working gas (i.e., volume of natural gas that can be injected and withdrawn from storage) to total gas consumption-has been consistently below $5 \%$ (Figure 1). This storage ratio is less than half the global average (12\%) and one-third of that in Europe (17\%) or North
America (16\%). ${ }^{34}$ Notably, even with a relatively high storage ratio, European countries are not immune to international natural gas supply disruptions. ${ }^{48,49}$ Therefore, China, the world's largest natural gas importer and the third largest natural gas consumer, ${ }^{15}$ is inevitably exposed to increasing natural gas insecurity.

Energy Sector Transformation Needed to Prepare for Natural Gas Import Disruptions. With China's current natural gas storage capacity, considerable challenges exist in preparing for international gas trade interruptions-particularly in regions and sectors with high natural gas dependence.

Figure 2 highlights the degree of energy efficiency improvement needed or the amount of alternative energy demand to prepare for natural gas import interruptions. As shown in Figure 2, an overall additional energy efficiency improvement of $1.5 \%$ is needed for the whole economy to meet the domestic gas supply deficiency; this equals an additional $\sim 30-70 \%$ of China's annual average efficiency improvement. ${ }^{50}$ Notable variations exist across regions and end-use sectors. For instance, across provinces, Beijing requires the most progressive efficiency improvement of up to $10 \%$, indicating its uniquely high natural gas share in the local energy structure (refer to Figure S2 for the spatial distribution of provinces in China). Nevertheless, if we assume that Beijing and Shanghai have higher priority in postdisruption gas reallocation, these two provinces could shift the efficiency improvement requirement to other provinces (e.g., Shanxi and Shaanxi), yet the national impacts stay almost the same (Figure S3). Among major end-uses, the residential (3\%) and industrial $(2 \%)$ sectors require the most significant efficiency improvement, particularly for urban residents (8\%).

Supposing a switch to alternative fuels across major end-uses to prepare for interrupted natural gas imports, approximately 56 million tonnes of coal equivalent $\left(\mathrm{MtCoal}_{\mathrm{eq}}\right)$ of domestic unconventional natural gas, $73 \mathrm{MtCoal}_{\mathrm{eq}}$ (including $\sim 95 \%$ coal) of domestic fossil fuels with current combustion, 66 $\mathrm{MtCoal}_{\mathrm{eq}}(\sim 95 \% \mathrm{coal})$ of domestic fossil fuels with cleaner combustion, or $96 \mathrm{MtCoal}_{\mathrm{eq}}(\sim 83 \%$ coal $)$ and $102 \mathrm{MtCoal}_{\mathrm{eq}}$ $(\sim 60 \%$ coal) of domestic electricity-generating energy under 2015 electrification and partially decarbonized electrification 

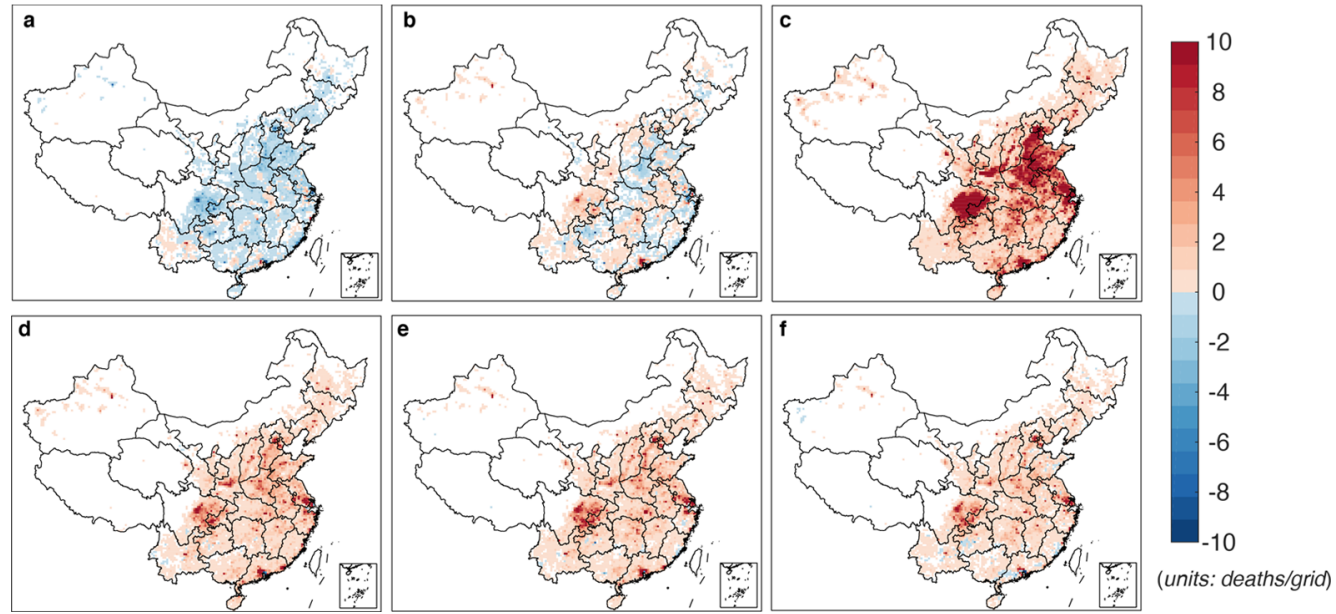

(units: deaths/grid)

Figure 4. Spatially resolved human health consequences under each scenario. Spatial distribution of $\mathrm{PM}_{2.5}$-associated premature deaths under each scenario: (a) efficiency improvement; (b) UN compensation; (c) AF compensation; (d) CF compensation; (e) 2015 electrification; and (f) partially decarbonized electrification. AF compensation causes the most substantial excess premature deaths, particularly in SCQ, BTH, Yangzi River Delta, and the Pearl River Delta regions.

are needed. These results correspond to $\sim 7$-fold increases in domestic unconventional gas (UN) production $(6.4 \mathrm{bcm}$ of total shale gas and SNG production in 2015$)^{51,52}$ or $\sim 2.1-$ $2.7 \%$ of additional coal consumption for the other four compensation scenarios. Under all scenarios, the industry and residential sectors require the most alternative fuels, where natural gas was initially mainly consumed. ${ }^{33}$ Notably, the residential sector makes up $\sim 20 \%$ of the sectoral total UN demand, whereas $\sim 30 \%$ of alternative $\mathrm{AF}$ fuels under both average and CF compensation scenarios, indicating that natural gas has been particularly efficient in substituting coal combustion in the residential sector. Apparently, the required improvement (e.g., the level of efficiency improvement) from each strategy to prepare for full gas import disruption demonstrates notable challenges, indicating the need for the simultaneous implementation of a mix of strategies.

Multiaspect Environmental Consequences to Prepare for Import Disruptions. Assuming successful implementation of each preparation strategy, the resulting environmental consequences range from slight improvement (i.e., efficiency improvement) to notable deterioration (i.e., AF compensation for natural gas supply deficiency).

Upgrading the end-use energy efficiency is the only scenario that can simultaneously reduce life cycle air pollutant emissions (i.e., $\sim 13$ kilotonnes of $\mathrm{SO}_{2}$, kt $\left.\mathrm{SO}_{2}\right)$, GHGs ( $\sim 95$ million tonnes of $\mathrm{CO}_{2}$ equivalent, $\mathrm{Mt} \mathrm{CO}_{2 \mathrm{eq}}$, under the $100 \mathrm{yr}$ global warming potential, $\left.\mathrm{GWP}_{100}\right)$, and water consumption $(\sim 113$ million cubic meters, $\mathrm{m}^{3}$ ) (Figure 3 ), as all other scenarios evaluated in this study require extra fossil fuel consumption to prepare for gas import disruptions. However, the potential environmental improvement with upgrading end-use efficiency is often much smaller than the environmental consequences of the other five scenarios. In particular, AF compensation results in the greatest increases in air pollutant emissions, which can be more than an order of magnitude larger (i.e., $\sim 760 \mathrm{kt}$ for $\mathrm{SO}_{2}$ ) than the corresponding reductions achieved by upgrading end-use efficiency mainly due to increased coal consumption to meet the gas supply deficiency. Increases in air pollutant emissions under CF compensation and 2015 electrification scenarios are comparable, roughly $20-70 \%$ of those under AF compensation (depending on the pollutant). Partially decar- bonized electrification can further cut air pollutant emission increases by $\sim 30 \%$ compared with the 2015 electrification. Changes in air pollutant emissions are often concentrated in major gas-producing provinces (i.e., Xinjiang and Sichuan) or populated eastern China (i.e., Shandong and Jiangsu) (Figures 3 and S4 and S5).

Across our evaluated scenarios, changes in GHG emissions and water consumption vary by $\sim 2-3$ times; while still large, these variations are much smaller than the differences in air pollutant emission changes. UN compensation and 2015 electrification result in the greatest increases in GHG emissions ( $\sim 175$ and $170 \mathrm{Mt} \mathrm{CO}_{2 \text { eq }}$, respectively) and water consumption ( $\sim 290$ and $270 \mathrm{Mm}^{3}$, respectively). This is because both UN production (e.g., hydraulic fracturing for shale gas production ${ }^{6}$ and water demand for coal-based SNG production $^{6}$ ) and electricity generation (e.g., cooling water $)^{41}$ consume substantial amounts of water while contributing considerable GHG emissions due to $\mathrm{CH}_{4}$ leakage during shale gas production ${ }^{4,6}$ and $\mathrm{CO}_{2}$ emissions in coal-based SNG production $^{4}$ or coal-dominated electricity generation. ${ }^{53}$ In particular, the highest increases in water consumption due to UN compensation primarily occur in regions that already have severe water scarcity where SNG projects are mainly operated and approved (i.e., Xinjiang and Inner Mongolia) ${ }^{54}$ (Figures 3 and S5). Interestingly, sectoral contributions to air pollutants, GHGs, and water consumption show notable variations (Figure S6), suggesting different targeted sectoral opportunities in addressing different environmental impacts.

Human Health Impacts to Prepare for Import Disruption. Following from changes in air pollutant emissions, the air quality and associated human health impacts due to the evaluated scenarios are particularly concerning under AF compensation. As shown in Figures 4 and 5, AF compensation causes 23,300 (95\% CI: 22,100-24,500) $\mathrm{PM}_{2.5^{-}}$ associated excess deaths due to considerable extra coal and oil consumption to compensate for gas supply deficiency, which are approximately 3.0 times that of CF compensation, 3.2 times that of 2015 electrification, 4.5 times that of partially decarbonized electrification, and 25 times that of UN compensation. Further, increased premature mortality under AF compensation is $\sim 10$ times the number of avoided 


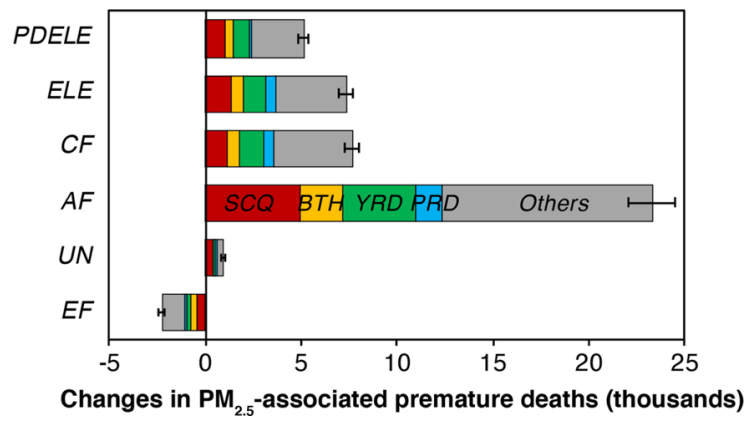

Figure 5. Excess $\mathrm{PM}_{2.5}$-associated premature deaths due to each scenario. EF: efficiency improvement; UN compensation; AF compensation; CF compensation; ELE: 2015 electrification; PDELE: partially decarbonized electrification. SCQ BTH, YRD, and PRD.

premature deaths due to efficiency improvement. These trends are consistent with the population-weighted $(\mathrm{P}-\mathrm{W}) \mathrm{PM}_{2.5}$ concentration changes across scenarios (Figure S7).

Such environmental and health outcomes are most problematic in Sichuan-Chongqing (SCQ), Beijing-Tianjin-Hebei (BTH), the Yangtze River Delta (YRD), and the Pearl River Delta (PRD) regions. Under AF compensation, $\mathrm{P}-\mathrm{W} \mathrm{PM}_{2.5}$ concentrations increase by $4.6 \mu \mathrm{g} / \mathrm{m}^{3}$ in Chongqing, $3.2 \mu \mathrm{g} / \mathrm{m}^{3}$ in Sichuan, and $2.0 \mu \mathrm{g} / \mathrm{m}^{3}$ in Beijing. The associated excess premature deaths are $4950(4710-5180)$ in SCQ 2250 (2140-2350) in BTH, 3730 (3540-3920) in YRD, and 1400 (1320-1490) in PRD regions. Notably, a potentially higher regional priority for postdisruption gas re-allocation in Beijing and Shanghai will reduce $\mathrm{PM}_{2.5}$-associated premature deaths in these two regions at the expense of increased excess deaths in provinces such as Shanxi and Shaanxi, and, thus, the national total numbers would only be slightly improved (23,100, 95\% CI: 21,900-24,300; Figure S8).

Between 2013 and 2017, China launched the Air Pollution Prevention and Control Action Plan (Clean Air Action), ${ }^{55}$ which cost approximately 240 billion U.S. dollars, ${ }^{56}$ reduced national annual average $\mathrm{PM}_{2.5}$ concentrations by $32 \%$, ${ }^{55}$ and thereby avoided $\sim 400,000$ air pollution-attributed deaths nationwide. ${ }^{55}$ However, if China were to prepare for international gas supply disruptions with AF compensation, this could partly offset the national air quality and human health improvements from the enormous economic and political investments in Clean Air Action. ${ }^{55}$ Even with progressive Clean Air Action efforts, China's air pollution remains severe; in 2017, 220 cities were still unable to meet the national $\mathrm{PM}_{2.5}$ air quality standard. ${ }^{55}$ Natural gas import disruptions could potentially further worsen the situation, especially among some of the most populated and polluted regions (e.g., SCQ BTH, YRD, and PRD), if the postdisruption gas re-allocation resembles the current pattern.

Other than improving the end-use energy efficiency, different strategies to prepare for gas import disruptions would trigger different levels of air quality and human health losses due to increased upstream (e.g., electrification scenarios) and/or end-use (e.g., fossil compensation scenarios) fossil fuel consumption. We thereby further evaluate the potential impacts under increased natural gas storage capacity and more progressive renewable energy development. As shown in Figure 6, expanding the current natural gas storage capacity to a higher level can notably reduce the negative environmental impacts across planning strategies. For instance, increases in air pollutant emissions, GHGs, and water consumption under a $15 \%$ storage ratio (slightly higher than the global average level) can be reduced to $60 \%$ of our estimates under the $5 \%$ storage ratio. In addition, as illustrated in Figure S9, with a $15 \%$ storage ratio, $\mathrm{PM}_{2.5}$-associated premature mortality under the AF compensation strategy decreased to 13,300 (95\% CI: $12,600-13,970$ ), reducing the human health impacts by $\sim 40 \%$. Therefore, gas storage expansion can play an important role in mitigating the environmental consequences from different preparation strategies. Nevertheless, despite such remarkable reductions, gas storage expansion alone is insufficient to address potential air quality and human health consequences. Under China's current energy structure and combustion technology, even with a $20 \%$ gas storage capacity, the air quality and health impacts from the AF compensation strategy are still larger than all other scenarios with a $5 \%$ storage ratio (Figure 6), which highlights the importance of a simultaneous
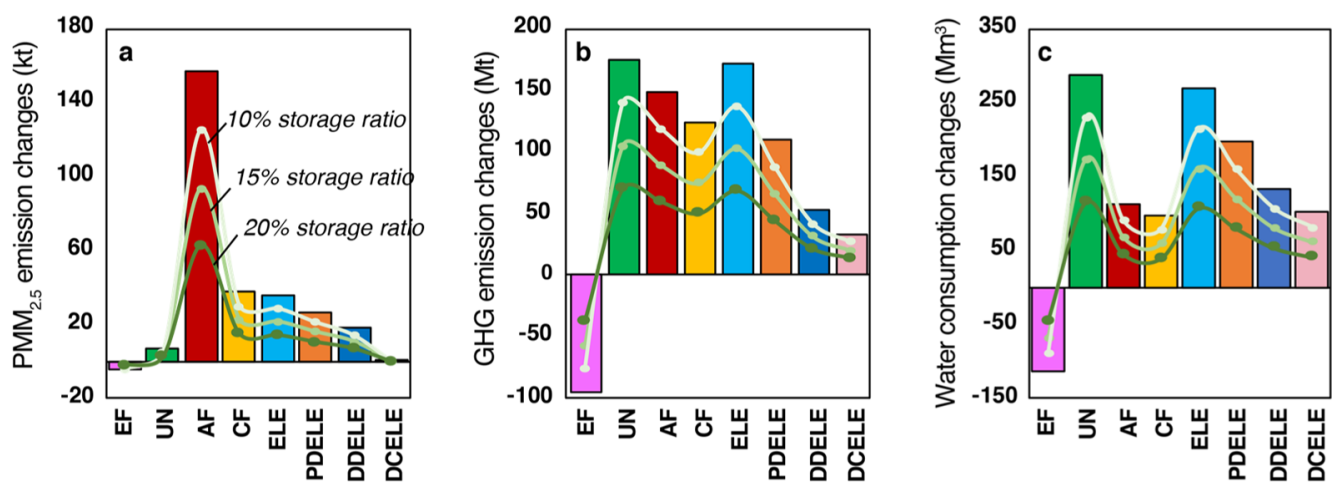

Figure 6. Changes in life cycle (a) $\mathrm{PM}_{2.5}$ emissions, (b) GHGs $\left(\mathrm{GWP}_{100}\right)$, and (c) water consumption for different scenarios with varying natural gas storage capacities. Bar charts represent results under the current gas storage ratio (5\%), light to dark green lines illustrate results under 10, 15 , and $20 \%$ gas storage ratios. EF: efficiency improvement; UN compensation; AF compensation; CF compensation; ELE: electrification with the 2015 power grid mix; PDELE: partially decarbonized electrification (43\% nonfossil energy and $57 \%$ fossi ${ }^{36}$ with the current combustion technology); DDELE: deeper decarbonized electrification (59\% nonfossil energy and $41 \%$ fossil ${ }^{36}$ with the current combustion technology); and DCELE: deeper decarbonized electrification with CF combustion ( $59 \%$ nonfossil energy and $41 \%$ fossil ${ }^{36}$ with the cleaner combustion technology). Expanding the natural gas storage capacity and promoting clean energy transition (i.e., improving efficiency and deeper electrification with decarbonized energy mix) are both needed to simultaneously address multiple environmental consequences related to preparing for international natural gas disruptions. 
effective clean energy transition (i.e., facilitating electrification with decarbonized fuel mix).

More progressive renewable developments with cleaner combustion technologies can significantly reduce the air pollution impacts, yet the climate and water consequences are still not negligible even with a $\sim 60 \%$ no-carbon energy mix (Figure 6). This indicates that even more ambitious energy sector decarbonization and low/no water-consuming renewable energies (e.g., wind and PV), together with gas storage expansion, would be needed to alleviate our identified multiaspect environmental consequences.

Policy Implications. Domestic air pollution ${ }^{57}$ along with global climate concerns ${ }^{2}$ has led to an increase in natural gas demand around the globe. ${ }^{1,58}$ This growing demand, however, is often built on an increasing dependence on international natural gas trade, which inevitably results in growing natural gas insecurity among gas-importing countries with underdeveloped storage capacities. Such insecurity is becoming increasingly problematic for China under intensifying U.S.China relations, which triggers serious concerns among China's top leadership and calls for self-reliance in China's energy system. ${ }^{23}$ Here, we hence focus on characterizing the multiaspect environmental impacts of a series of potential planning strategies to better inform policy-making via linking the environmental consequences with national energy security.

We find that, other than progressive energy efficiency improvement, all scenarios we evaluate could result in simultaneous degradation of domestic air quality, local water scarcity, and the global climate due to increasing upstream and/or end-use fossil fuel consumption. In particular, preparing for domestic gas deficiency due to potential import disruptions with China's current energy mix (AF compensation) could result in an increase of 23,300 (22,100-24,500) premature deaths from $\mathrm{PM}_{2.5}$, particularly in heavily polluted yet populated eastern provinces and Sichuan-Chongqing regions. This preparation strategy could potentially partly offset the air quality and human health improvements achieved by China's Clean Air Action. Although shifting the gas disruption burden across provinces (e.g., compensating for the gas deficiency in Beijing and Shanghai from other provinces) helps to alleviate the environmental consequences in provinces with higher political and economic priorities, it does not bring much improvement at the national level. CF, UN, and electrification scenarios can significantly lower the air pollution and associated health impacts from AF compensation, yet some of them may lead to higher climate and water penalties. $\mathrm{AF}$ compensation is thus the least favorable preparation strategy regarding air quality and the associated human health impacts. However, it may be a relatively easy-to-implement strategy, especially considering the scale and pace of additional improvement needed in upgrading end-use efficiency, ${ }^{59}$ cleaning end-uses, ${ }^{60}$ and electrifying the economy, as well as the slower-than-expected domestic UN development. ${ }^{47}$ Yet, it is possible that a supply shortage with another type of energy (e.g., coal and power) could limit the ability to rely on other energy sources to prepare for potential natural gas import disruptions. Overall, it is likely that these preparation strategies will be implemented in different combinations across the country. Therefore, the actual environmental impacts will depend on the implementation level of each strategy, highlighting the value of focusing on improving end-use energy efficiency, more progressive renewable energy development, and expanding natural gas storage capacity.
Our study analyzes the environmental consequences of potential preparation for import disruptions on an annual basis. Assuming preparation for a shorter period of import disturbance, the potential environmental outcomes may demonstrate significant seasonal variations, with winter gas disruptions likely to have the largest negative consequences (as indicated in Figure S10). Growing seasonal heterogeneities in gas demand alone provide an additional incentive to expand natural gas storage capacity. ${ }^{47}$ Nevertheless, if international gas supply disruptions become a new norm, energy efficiency improvement and renewable energy development could become even more important in minimizing the environmental consequences related to import disruptions, as gas storage infrastructure may be subject to insufficient natural gas reinjection. Long-term gas import disturbance will eventually reshape China's energy demand and market responses, and follow-up studies should also evaluate the resulting impacts on China's postdisruption responding strategies and the corresponding environmental consequences.

Despite China's progressive efforts to transform the energy sector, coal still dominates its energy mix up to 2018 (58\% vs $7 \%$ for natural gas). ${ }^{33}$ Natural gas will continue to be an essential substitute for coal over the next decade or longer. As of 2018, China's foreign gas dependence has increased by 15 percentage points since 2015, the data of which are the basis of this analysis. Thus, the $45 \%$ gas dependence could result in an additional $60 \%$ increase in the environmental impacts we estimated here (Figure S11), or the estimates presented here represent $\sim 67 \%$ of international gas disruptions in 2018 . Nevertheless, continuous air pollution control technologies have also been implemented after 2015, which could partly offset the growing environmental loss that resulted from rising external dependence. Here, we focus on unraveling the multiaspect environmental impacts due to natural gas import disruptions to ensure gas supply self-reliance; meanwhile, efforts such as strategically diversifying import sources will help reduce natural gas supply insecurity to start with. The integrated framework and conclusions from our work will be broadly applicable to other countries with similar developments with respect to a growing reliance on imported natural gas (i.e., over 50\% import gas dependence in India in $2019^{61}$ ).

This trend of continuously growing import dependence can aggravate negative environmental consequences, highlighting the importance of developing domestic natural gas storage capacity, and more importantly continue transforming its energy structure (i.e., improving energy efficiency and facilitating electrification with an increasingly decarbonized energy mix), to minimize the environmental impacts to offset the supply uncertainties in international energy markets. Clearly, upgrading the energy system (i.e., efficiency improvement and decarbonization) is in line with China's most recent pledge of achieving carbon peak before 2030 and being carbonneutral by 2060 . Thus, even without the risk of import disruptions, such strategies are good in themselves for regional and global environment. Yet, preparing for natural gas supply disruptions provides additional incentives to facilitate efficiency improvement and progressive decarbonization. However, it is worth noting that although renewable development can play an important role in alleviating energy security rooted in high external natural gas dependence, some renewable energies (e.g., wind and solar) may lead to new security issues such as electricity supply variability and cybersecurity, which call for 
cautious assessment and planning adaptation strategies (e.g., cost-competitive energy storage). ${ }^{2}$

Disputes exist regarding the natural gas "lock-in" effect. Unlike the situation in the U.S. and EU, China's natural gas storage is significantly underdeveloped, and natural gas is primarily used to substitute for coal. Meanwhile, the natural gas network can potentially integrate with decarbonized energy systems either as a backup for variable wind and solar energies ${ }^{63}$ or be retrofitted for hydrogen storage. ${ }^{64}$ As such, a cautious investment in natural gas infrastructure with strict methane leakage regulations in China in this decade is unlikely to be regretted. That said, increasing investment in energy efficiency improvement and domestic renewable energy in combination with energy storage is likely to be a better longterm choice, considering the overall benefits.

This study, by systematically characterizing the multiaspect environmental consequences of China's potential preparation strategies for natural gas import disruptions, provides essential incentives for countries such as China to carefully plan ahead for energy sector adaptation under increasing dependence on energy imports, as well as the growing international political uncertainties.

\section{ASSOCIATED CONTENT}

\section{SI Supporting Information}

The Supporting Information is available free of charge at https://pubs.acs.org/doi/10.1021/acs.est.1c03685.

Details of energy sector preparation scenarios design, life cycle environmental impacts estimation; energy efficiency data and fuel economy parameters; changes in air pollutant emissions, GHGs, and water use; modelsimulated air pollution concentrations; and human health impacts for different scenarios (PDF)

\section{AUTHOR INFORMATION}

\section{Corresponding Author}

Yue Qin - College of Environmental Science and Engineering, Peking University, Beijing 100871, China; 이이.org/ 0000-0003-1664-4516; Email: qinyue@pku.edu.cn

\section{Authors}

Mi Zhou - Laboratory for Climate and Ocean-Atmosphere Studies, Department of Atmospheric and Oceanic Sciences, School of Physics, Peking University, Beijing 100871, China; Princeton School of Public and International Affairs, Princeton University, Princeton, New Jersey 08544, United States

Da Pan - Department of Civil and Environmental Engineering, Princeton University, Princeton, New Jersey 08544, United States

Zbigniew Klimont - International Institute for Applied Systems Analysis, Laxenburg A-2361, Austria

Daniel B. Gingerich - Department of Civil, Environmental, and Geodetic Engineering, Department of Integrated Systems Engineering, and Sustainability Institute, The Ohio State University, Columbus, Ohio 43210, United States

Denise L. Mauzerall - Princeton School of Public and International Affairs and Department of Civil and Environmental Engineering, Princeton University, Princeton, New Jersey 08544, United States; 이이.org/0000-0003$3479-1798$
Lei Zhao - Department of Civil and Environmental Engineering, University of Illinois at Urbana-Champaign, Urbana, Illinois 61801, United States

Gang He - Department of Technology and Society, College of Engineering and Applied Sciences, Stony Brook University, Stony Brook, New York 11794, United States; (1) orcid.org/ 0000-0002-8416-1965

Jeffrey M. Bielicki - Department of Integrated Systems Engineering, Sustainability Institute, and John Glenn College of Public Affairs, The Ohio State University, Columbus, Ohio 43210, United States; (1) orcid.org/0000-0001-8449-9328

Complete contact information is available at:

https://pubs.acs.org/10.1021/acs.est.1c03685

\section{Notes}

The authors declare no competing financial interest.

\section{ACKNOWLEDGMENTS}

This study is supported by the 111 Project Urban Air Pollution and Health Effects (B20009).

\section{REFERENCES}

(1) International Energy Agency. World Energy Outlook 2011 Special Report. Are we entering a golden age of gas? https://www.iea. $\mathrm{org} /$ reports/weo-special-report-are-we-entering-a-golden-age (accessed March 12, 2021).

(2) Liu, Z.; Guan, D.; Crawford-Brown, D.; Zhang, Q.; He, K.; Liu, J. A low-carbon road map for China. Nature 2013, 500, 143-145.

(3) Brown, S. P. A., Krupnick, A. J., Walls, M. A. Natural Gas: A bridge to a low-carbon future; Resources For The Future. 2009, https://media.rff.org/archive/files/sharepoint/Documents/Events/ $110921 \mathrm{Sh}$ a 1 e G a s / 2

\%20Is\%20Natural\%20Gas\%20a\%20Bridge\%20to\%20a\%20Low\%20 Carbon\%20Future.pdf (accessed July 20, 2021).

(4) Qin, Y.; Wagner, F.; Scovronick, N.; Peng, W.; Yang, J.; Zhu, T.; Smith, K. R.; Mauzerall, D. L. Air quality, health, and climate implications of China's synthetic natural gas development. Proc. Natl. Acad. Sci. U.S.A. 2017, 114, 4887-4892.

(5) Yang, C.-J.; Jackson, R. B. Commentary: China's Synthetic Natural Gas Revolution. Nat. Clim. Change 2013, 3, 852-854.

(6) Qin, Y.; Höglund-Isaksson, L.; Byers, E.; Feng, K.; Wagner, F.; Peng, W.; Mauzerall, D. L. Air quality-carbon-water synergies and trade-offs in China's natural gas industry. Nat. Sustain. 2018, 1, 505511.

(7) Alvarez, R. A.; Pacala, S. W.; Winebrake, J. J.; Chameides, W. L.; Hamburg, S. P. Greater focus needed on methane leakage from natural gas infrastructure. Proc. Natl. Acad. Sci. U.S.A. 2012, 109, 6435-6440.

(8) Wigley, T. M. L. Coal to gas: the influence of methane leakage. Climatic Change 2011, 108, 601-608.

(9) Höglund-Isaksson, L.; Gómez-Sanabria, A.; Klimont, Z.; Rafaj, P.; Schöpp, W. Technical potentials and costs for reducing global anthropogenic methane emissions in the 2050 timeframe -results from the GAINS model. Environ. Res. Commun. 2020, 2, 025004.

(10) Burney, J. A. The downstream air pollution impacts of the transition from coal to natural gas in the United States. Nat. Sustain. 2020, 3, 152-160.

(11) International Energy Agency. Gas. 2019, https://www.iea.org/ fuels-and-technologies/gas (accessed Sept 16, 2020).

(12) U.S. Energy Information Administration. Natural Gas Market Production. https://www.eia.gov/dnav/ng/hist/n9050us2a.htm (accessed 2021-03-15).

(13) Joskow, P. L. Natural Gas: From Shortages to Abundance in the United States. Am. Econ. Rev. 2013, 103, 338-343.

(14) Cabalu, H. Indicators of security of natural gas supply in Asia. Energy Pol. 2010, 38, 218-225. 
(15) Energy Information Administration. International Natural Gas. https://www.eia.gov/international/data/world/natural-gas/drynatural-gas-production? $\mathrm{pd}=3002 \& \mathrm{p}=00 \mathrm{~g} \& \mathrm{u}=0 \mathrm{\&} \mathrm{f}=\mathrm{A} \& \mathrm{v}=$ $\mathrm{mapbubble} \& \mathrm{a}=-\& \mathrm{i}=\mathrm{n}$ on e $\& \mathrm{vo}=\mathrm{valu}$ e \& \& $\mathrm{t}=\mathrm{C} \& \mathrm{~g}=$ $00000000000000000000000000000000000000000000000001 \& \mathrm{l}=$ 249-ruvvvvvfvtvnvv 1 vrvvvvffvvvvvvfvvvou 20 evvvvvvvvvvvvvvvvs\&s= $315532800000 \& \mathrm{e}=1483228800000$ (accessed Sept 20, 2020).

(16) International Energy Agency. Energy Supply Security 2014: Emergency Response of IEA Countries. https://iea.blob.core. windows.net/assets/73908149-4d6e-4f10-b626-d55c60ab3bd7/ ENERGYSUPPLYSECURITY2014.pdf (accessed July 20, 2021).

(17) Kong, Z.; Lu, X.; Jiang, Q.; Dong, X.; Liu, G.; Elbot, N.; Zhang, Z.; Chen, S. Assessment of import risks for natural gas and its implication for optimal importing strategies: A case study of China. Energy Pol. 2019, 127, 11-18.

(18) Shaikh, F.; Ji, Q.; Fan, Y. Evaluating China's natural gas supply security based on ecological network analysis. J. Clean. Prod. 2016, $139,1196-1206$.

(19) Ding, Y.; Zhang, M.; Chen, S.; Nie, R. Assessing the resilience of China's natural gas importation under network disruptions. Energy 2020, 211, 118459 .

(20) Dong, X.; Kong, Z. The impact of China's natural gas import risks on the national economy. J. Nat. Gas Sci. Eng. 2016, 36, 97-107.

(21) Chai, J.; Wei, Z.; Hu, Y.; Su, S.; Zhang, Z. G. Is China's natural gas market globally connected? Energy Pol. 2019, 132, 940-949.

(22) Liu, S. Q.; Huang, X.; Li, X.; Masoud, M.; Chung, S.-H.; Yin, Y. How is China's energy security affected by exogenous shocks? Evidence of China-US trade dispute and COVID-19 pandemic. Discov. Energy 2021, 1, 1-23.

(23) Downs, E. High Anxiety: The trade war and China's Oil and Gas Supply Security; Columbia Center on Global Energy Policy I SIPA. https://energypolicy.columbia.edu/sites/default/files/fileuploads/ChinaTradeWar_CGEP_Commentary_111519.pdf (accessed July 20, 2021).

(24) Zhang, M.; Su, W.; Su, C. An Assessment of the Security of China's Natural Gas Supply System Using Two Network Models. Energies 2015, 8, 13710-13725.

(25) Lu, W.; Su, M.; Fath, B. D.; Zhang, M.; Hao, Y. A systematic method of evaluation of the Chinese natural gas supply security. Appl. Energy 2016, 165, 858-867.

(26) Guo, M.; Bu, Y.; Cheng, J.; Jiang, Z. Natural Gas Security in China: A Simulation of Evolutionary Trajectory and Obstacle Degree Analysis. Sustainability 2019, 11, 96-114.

(27) Zhang, L.; Bai, W. Risk Assessment of China's Natural Gas Importation: A Supply Chain Perspective. Sage Open 2020, 10, 215824402093991.

(28) Lu, W.; Su, M.; Fath, B. D.; Zhang, M.; Hao, Y. A systematic method of evaluation of the Chinese natural gas supply security. Appl. Energy 2016, 165, 858-867.

(29) IPCC. Climate Change 2014: Mitigation of Climate Change. Contribution of Working Group III to the Fifth Assessment Report of the Intergovernmental Panel on Climate Change; Edenhofer, O., PichsMadruga, R., Sokona, Y., Farahani, E., Kadner, S., Seyboth, K., Adler, A., Baum, I., Brunner, S., Eickemeier, P., Kriemann, B., Savolainen, J., Schlömer, S., von Stechow, C., Zwickel, T., Minx, J. C., Eds.; Cambridge University Press; Cambridge, United Kingdom and New York, NY, USA, 2014.

(30) Jewell, J.; Cherp, A.; Vinichenko, V.; Bauer, N.; Kober, T.; Mccollum, D.; Van Vuuren, D. P.; Van Der Zwaan, B.; van der Zwaan, B. Energy security of China, India, the E.U. and the U.S. under longterm scenarios: Results from six IAMs. Clim. Change Econ. 2013, 04, 1340011.

(31) Chaturvedi, V. Energy security and climate change: Friends with asymmetric benefits. Nat. Energy 2016, 1, 16075.

(32) Jewell, J.; Vinichenko, V.; McCollum, D.; Bauer, N.; Riahi, K.; Aboumahboub, T.; Fricko, O.; Harmsen, M.; Kober, T.; Krey, V.; Marangoni, G.; Tavoni, M.; Van Vuuren, D. P.; Cherp, A.; et al. Comparison and interactions between the long-term pursuit of energy independence and climate policies. Nat. Energy 2016, 1, 16073.
(33) National Bureau of Statistics of China. National Statistic Data. http://data.stats.gov.cn/easyquery.htm? $\mathrm{cn}=\mathrm{C} 01$ (accessed July 16, 2021).

(34) Lei, H. Opportunities and challenges to the construction of underground gas storages in China. Oil Gas Storage Transp. 2018, 37, $728-733$.

(35) China Electric Power Yearbook Committee. China's Electricity Statistic Yearbook, 2016. https://data.cnki.net/Trade/yearbook/ single/N2019060101?z=Z025 (accessed July 18, 2021).

(36) International Energy Agency. World Energy Outlook 2020. www.iea.org (accessed July 20, 2021).

(37) Wu, M.; Mintz, M.; Wang, M.; Arora, S.; Chiu, Y.-W.; Xu, H., Consumptive Water Use in the Production of Ethanol and Petroleum Gasoline: 2018 Update. Argonne National Laboratory Technical Report, ANL/ESD-09/01 Rev. 2; Argonne National Laboratory: Lemont, IL, U.S.A. https://publications.anl.gov/anlpubs/2019/01/ 148043.pdf (accessed July 18, 2021).

(38) Ou, X.; Zhang, X.; Chang, S. Alternative fuel buses currently in use in China: Life-cycle fossil energy use, GHG emissions and policy recommendations. Energy Pol. 2010, 38, 406-418.

(39) Stohl, A.; Aamaas, B.; Amann, M.; Baker, L. H.; Bellouin, N.; Berntsen, T. K.; Boucher, O.; Cherian, R.; Collins, W.; Daskalakis, N.; Dusinska, M.; Eckhardt, S.; Fuglestvedt, J. S.; Harju, M.; Heyes, C.; Hodnebrog, Ø.; Hao, J.; Im, U.; Kanakidou, M.; Klimont, Z.; Kupiainen, K.; Law, K. S.; Lund, M. T.; Maas, R.; MacIntosh, C. R.; Myhre, G.; Myriokefalitakis, S.; Olivié, D.; Quaas, J.; Quennehen, B.; Raut, J.-C.; Rumbold, S. T.; Samset, B. H.; Schulz, M.; Seland, Ø.; Shine, K. P.; Skeie, R. B.; Wang, S.; Yttri, K. E.; Zhu, T. Evaluating the climate and air quality impacts of short-lived pollutants. Atmos. Chem. Phys. 2015, 15, 10529-10566.

(40) Klimont, Z.; Kupiainen, K.; Heyes, C.; Purohit, P.; Cofala, J.; Rafaj, P.; Borken-Kleefeld, J.; Schöpp, W. Global anthropogenic emissions of particulate matter including black carbon. Atmos. Chem. Phys. 2017, 17, 8681-8723.

(41) Qin, Y.; Mueller, N. D.; Siebert, S.; Jackson, R. B.; AghaKouchak, A.; Zimmerman, J. B.; Tong, D.; Hong, C.; Davis, S. J. Flexibility and intensity of global water use. Nat. Sustain. 2019, 2, 515-523.

(42) Grell, G. A.; Peckham, S. E.; Schmitz, R.; McKeen, S. A.; Frost, G.; Skamarock, W. C.; Eder, B. Fully coupled "online" chemistry within the WRF model. Atmos. Environ. 2005, 39, 6957-6975.

(43) Zhou, M.; Liu, H.; Peng, L.; Qin, Y.; Chen, D.; Zhang, L.; Mauzerall, D. L. Air Quality, Health, Carbon, and Cost Implications of Alternative Clean Heating Options in Northern China, 2021, DOI: $10.1038 /$ s41893-021-00837-w. In Press.

(44) Zhou, M.; Zhang, L.; Chen, D. The impact of aerosol-radiation interactions on the effectiveness of emission control measures. Environ. Res. Lett. 2018, 14, 024002.

(45) Chen, D.; Liu, Z.; Fast, J.; Ban, J. Simulations of sulfatenitrate-ammonium (SNA) aerosols during the extreme haze events over northern China in October 2014. Atmos. Chem. Phys. 2016, 16, 10707-10724.

(46) Burnett, R.; Chen, H.; Szyszkowicz, M.; Fann, N.; Hubbell, B.; Pope, C. A., 3rd; Apte, J. S.; Brauer, M.; Cohen, A.; Weichenthal, S.; Coggins, J.; Di, Q.; Brunekreef, B.; Frostad, J.; Lim, S. S.; Kan, H.; Walker, K. D.; Thurston, G. D.; Hayes, R. B.; Lim, C. C.; Turner, M. C.; Jerrett, M.; Krewski, D.; Gapstur, S. M.; Diver, W. R.; Ostro, B.; Goldberg, D.; Crouse, D. L.; Martin, R. V.; Peters, P.; Pinault, L.; Tjepkema, M.; van Donkelaar, A.; Villeneuve, P. J.; Miller, A. B.; Yin, P.; Zhou, M.; Wang, L.; Janssen, N. A. H.; Marra, M.; Atkinson, R. W.; Tsang, H.; Quoc Thach, T.; Cannon, J. B.; Allen, R. T.; Hart, J. E.; Laden, F.; Cesaroni, G.; Forastiere, F.; Weinmayr, G.; Jaensch, A.; Nagel, G.; Concin, H.; Spadaro, J. V. Global estimates of mortality associated with long-term exposure to outdoor fine particulate matter. Proc. Natl. Acad. Sci. U.S.A. 2018, 115, 9592-9597.

(47) Qin, Y.; Tong, F.; Yang, G.; Mauzerall, D. L. Challenges of using natural gas as a carbon mitigation option in China. Energy Pol. 2018, 117, 457-462. 
(48) Koranyi, D. The strategic role of the US in European energy security. Nat. Energy 2016, 1, 16160.

(49) Lochner, S. Modeling the European natural gas market during the 2009 Russian-Ukrainian gas conflict: Ex-post simulation and analysis. J. Nat. Gas Sci. Eng. 2011, 3, 341-348.

(50) International Energy Charter. China Energy Efficiency Report. Protocol on Energy Efficiency and Environmental Aspects, 2018. https://www.energycharter.org/fileadmin/DocumentsMedia/EERR/ EER-China_ENG.pdf (accessed July 16, 2021).

(51) National Energy Administration. 13th Five-Year-Plan for Coal Deep-Processing Industry. https://www.ndrc.gov.cn/fggz/fzzlgh/ gjjzxgh/201708/W020191104624397843652.pdf (accessed July 16, 2021).

(52) Ministry of Land and Resources. Shale gas output increased by $258.5 \%$ in 2015. http://energy.people.com.cn/n1/2016/0411/ c71661-28265387.html (accessed July 16, 2021).

(53) Tong, D.; Zhang, Q.; Zheng, Y.; Caldeira, K.; Shearer, C.; Hong, C.; Qin, Y.; Davis, S. J. Committed emissions from existing energy infrastructure jeopardize 1.5 degrees C climate target. Nature 2019, 572, 373.

(54) Feng, K.; Hubacek, K.; Pfister, S.; Yu, Y.; Sun, L. Virtual Scarce Water in China. Environ. Sci. Technol. 2014, 48, 7704-7713.

(55) Zhang, Q.; Zheng, Y.; Tong, D.; Shao, M.; Wang, S.; Zhang, Y.; Xu, X.; Wang, J.; He, H.; Liu, W.; Ding, Y.; Lei, Y.; Li, J.; Wang, Z.; Zhang, X.; Wang, Y.; Cheng, J.; Liu, Y.; Shi, Q.; Yan, L.; Geng, G.; Hong, C.; Li, M.; Liu, F.; Zheng, B.; Cao, J.; Ding, A.; Gao, J.; Fu, Q.; Huo, J.; Liu, B.; Liu, Z.; Yang, F.; He, K.; Hao, J. Drivers of improved PM2.5 air quality in China from 2013 to 2017. Proc. Natl. Acad. Sci. U.S.A. 2019, 116, 24463-24469.

(56) Zhang, J.; Jiang, H.; Zhang, W.; Ma, G.; Wang, Y.; Lu, Y.; Hu, X.; Zhou, J.; Peng, F.; Bi, J.; Wang, J. Cost-benefit analysis of China's Action Plan for Air Pollution Prevention and Control. Front. Eng. Manag. 2019, 6, 524-537.

(57) Huang, X.; Ding, A.; Wang, Z.; Ding, K.; Gao, J.; Chai, F.; Fu, C. Amplified transboundary transport of haze by aerosol-boundary layer interaction in China. Nat. Geosci. 2020, 13, 428-434.

(58) International Energy Agency. World Energy Outlook Special Report on Unconventional Gas. Golden Rules for a Golden Age of Gas, 2011. https://iea.blob.core.windows.net/assets/8422ef9a-9ae84637-ab1c-ddb160ab7c59/WEO 2012 Special Report Golden Rules for_a_Golden_Age of_Gas.pdf (accessed July 18, 2021).

(59) International Energy Agency. Energy efficiency in China, 2018. https://www.iea.org/articles/energy-efficiency-in-china (accessed Sept 20, 2020).

(60) World Electric Power Plants (WEPP) Database (2017 Version). https://www.platts.com/products/world-electric-powerplants-database (accessed Sept 16, 2020).

(61) U.S. Energy Information Administration. Growth in India's LNG imports will depend on completion of connecting pipelines, 2020. https://www.eia.gov/todayinenergy/detail.php?id=43655 (accessed July 16, 2021).

(62) International Energy Agency. Net Zero by 2050: A Roadmap for the Global Energy Sector. https://www.iea.org/commentaries/acloser-look-at-the-modelling-behind-our-global-roadmap-to-net-zeroemissions-by-2050 (accessed Aug 1, 2021).

(63) Anderson, D.; Leach, M. Harvesting and redistributing renewable energy: on the role of gas and electricity grids to overcome intermittency through the generation and storage of hydrogen. Energy Policy 2004, 32, 1603-1614.

(64) Tarkowski, R. Underground hydrogen storage: Characteristics and prospects. Renewable Sustainable Energy Rev. 2019, 105, 86-94.

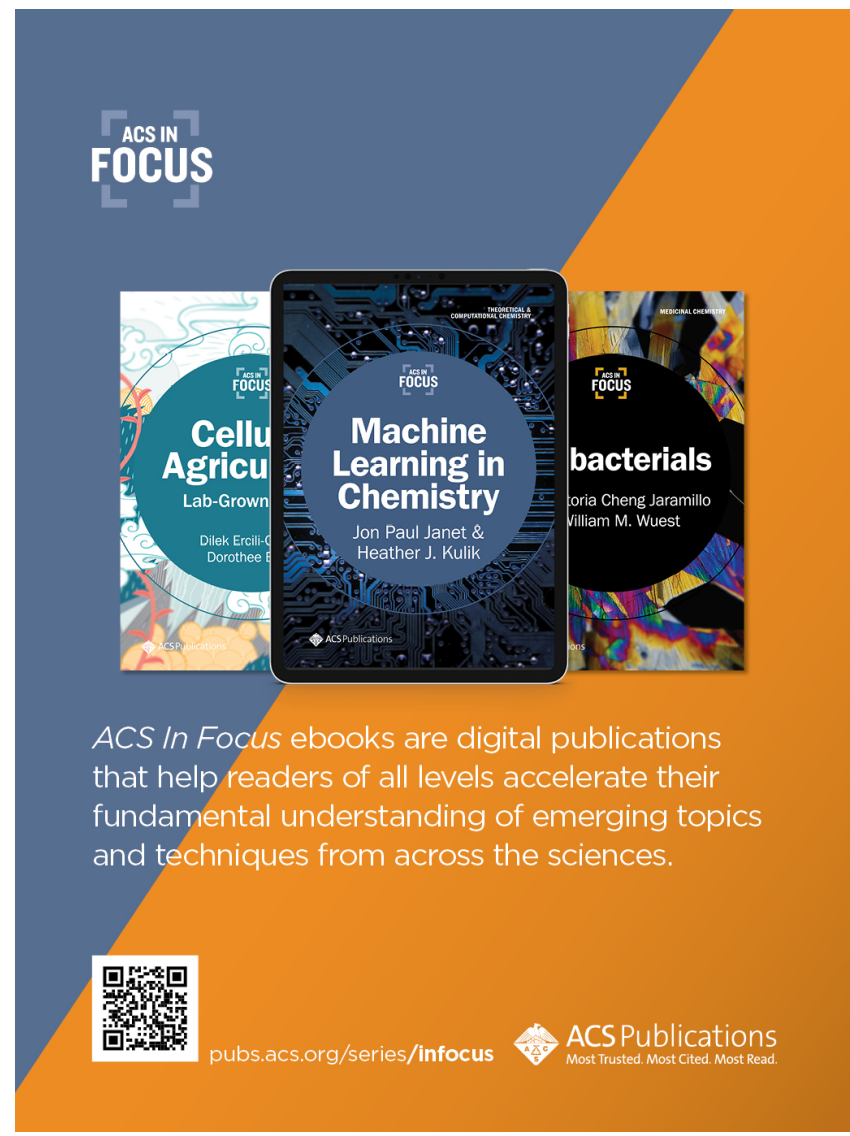

